open-minded members of the conference must have taken away, as well as their copies of Poston and Stewart's little red book, and the good resolution to think more geometrically, much benefit from the chance to talk with people from a remarkably wide range of disciplines.

\section{Venus is another differentiated planet}

\section{from G. Fielder}

Many scientists were surprised to find that the Moon was a differentiated planet. Now, in situ measurements of parts of the surface layers of Venus have indicated that the Earth's "sister" planet is more like the Earth than the Moon in its radioactive element content. Whereas measurements of the potassium, uranium, and thorium concentrations made in October 1975 using Veneras 9 and 10 indicated the presence of basaltic type rocks, earlier results from Venera 8 (July 1972) had indicated the presence elsewhere of rocks similar in their radioactivity to that of a typical terrestrial granite.

Writing with K. P. Florenskii, A. T. Bazilevskii and A. S. Selivanov in Doklady Akad. Nauk. SSSR (228, 570; 1976 ) the late A. N. Vinogradov has reported studies of the photographic panoramas and other data transmitted from Veneras 9 and 10 by way of a relay satellite. Telecameras mounted $1 \mathrm{~m}$ above the surface took high Sun photographs, including the one reconstructed in Fig. 1, with a resolution of about $1 / 3$ degree. So effective was the

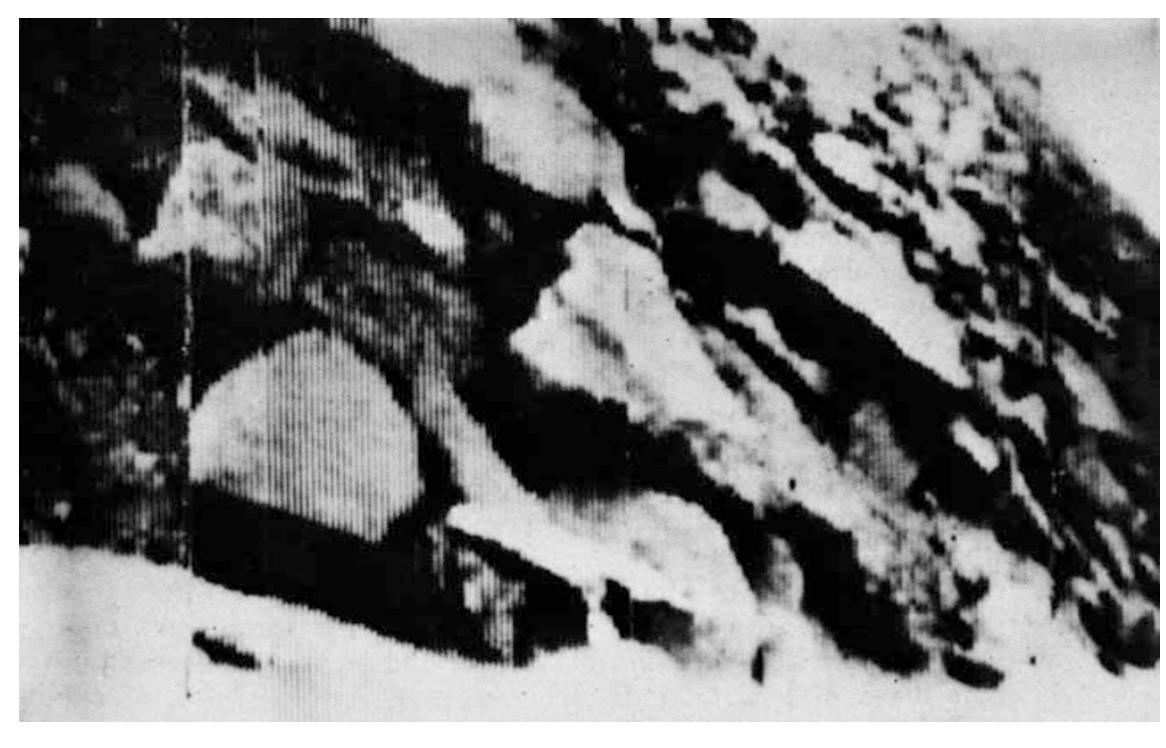

Fig. 1 Part of Venera 9 panorama. The rotation axis of the telecamera was inclined at $\sim 40^{\circ}$ to the vertical axis of the landing stage. The rocks shown here lie on, and form, a steep dense atmosphere of Venus in diffusing the weak light at ground level that high contrast versions of the photographs show "artificial shadows" which always point towards the appropriate camera.

The upper right hand corner of Fig. 1 shows the skyline, estimated to be several tens of metres distant. The sharpness of the skyline indicates a fairly high atmospheric transparency and, consequently, a comparatively low dust content. If any wind had been blowing across the surface when the pictorial data were transmitted, the wind had not been dust laden. Nevertheless, the authors have suggested that the clod-like nature of the dark soil filling the spaces between the numerous rock blocks may have resulted, in part, from the evacuation of fine particles by a weak wind. An alternative explanation, they suggest, is that the clods were produced following hydration of the particles.

Typically, the rock blocks themselves have dimensions of some tens of centimetres. Some are angular, others rounded. Many indicate that they have been detached from hard, layered bedrock. Others, which appear to be mostly buried, could even be outcrops of bedrock. A few rocks have cracks which cross the bedding plane. Others appear to be vesicular.

Together with the knowledge from radio observations that the surface layers of Venus are underdense, the picture data establish that certain dynamic processes are in operation there now. If the corrosive agents hydrochloric acid and hydrofluoric acid observed in the upper atmosphere of Venus are present at ground level they could be an important factor in the rounding and disintegration of the

rounding and disintegration of the

slope (the on-board inclinometer reading was $\sim 30^{\circ}$ ). Data auxiliary to the picture data were transmitted in vertical bands which have been removed. rocks to generate the soil. Whatever the predominant mechanism of denudation on Venus, it is clear from the abundance of sharply sculptured rocks on the surface where Venera 9 landed that this is a geologically young area of the planet.

The clouds of Venus, which prevent our viewing its surface directly, are found at up to $70 \mathrm{~km}$ above the surface. Most meteoroids of the present day populations would probably disintegrate in the thick, dense atmosphere $\left(97 \% \mathrm{CO}_{2}\right)$ before reaching the surface so that recent disturbances of the rocks of Venus are likely to be of internal origin. Now that two panoramas of the surface of Venus have shown scenes not unlike those of terrestrial desert landscapes, the next step will be to discover the processes which moulded the landforms of Venus.

\section{So Madagascar was to the north}

\section{from Peter J. Smith}

IN a recent article on the Madagascar controversy, Kent and Tarling (Nature, 261,304 ; 1976) were adamant in claiming that "the Madagascar controversy still lives". They were right of course, even excluding the element of selffulfilling prophesy. To expect everyone to accept that "palaeomagnetism has provided the definitive answer" to the Madagascar problem (Nature, 259, 80 ; 1976) was evidently overoptimistic, or at least premature. The controversy does indeed live. But for how much longer in the light of a new palaeomagnetic analysis from McElhinney et al. (Geology, 4, 455; 1976)?

The long-standing argument is, of course, over the geographical position of Madagascar before the breakup of Gondwanaland. Did this large island lie in the coastal embayment of Mozambique some $4^{\circ}$ south of its present position? Or was it about $15^{\circ}$ north, adjacent to the coast of KenyaTanzania-Somalia? Or has it always been where it is with respect to Africa, except perhaps for just a small amount of eastward drift? The answer is critical in defining the fit of eastern and western Gondwanaland. Evidence of various types has been adduced in favour of all three positions at various times, although clearly no more than one of the options can be correct.

The problem seemed well on the way to solution earlier this year when Embleton and McElhinney (Earth planet. Sci. Lett., 27, 329; 1976) presented palaeomagnetic data supporting the southward drift of Madagascar- 